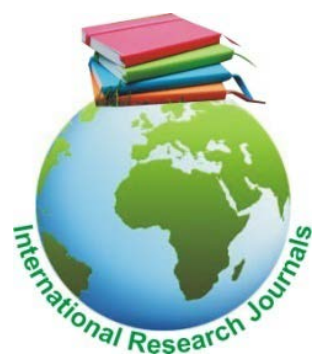

Full Length Review Paper

Journal of Research in Environmental Science and Toxicology Vol. 7(2) pp. 27-36, Nov, 2018

DOI: http:/dx.doi.org/10.14303/jrest.2018.017

Available online http://www.interesjournals.org/JREST

Copyright (C2018 International Research Journals

\title{
Dispersion of ancient humans in east Asia during the late Pleistocene: Geography, archaeology and ecology
}

\author{
Guan Ying ${ }^{1,2 *}$, Zhou Zhenyu ${ }^{3}$
}

${ }^{1}$ Key Laboratory of Vertebrate Evolution and Human Origins of Chinese Academy of Sciences, Institute of Vertebrate Paleontology and Paleoanthropology, Chinese Academy of Sciences, Beijing, China

${ }^{2}$ CAS Center for Excellence in Life and Pale environment, Beijing, China

${ }^{3}$ Institute of Archaeology, Chinese Academy of Social Sciences, Beijing, China

E-mail: guanying@ivpp.ac.cn

\begin{abstract}
During the late Pleistocene, external population entered East Asia through four possible migration routes and introduced Levallois and blade techniques into China. Most sites in China with these external lithic technology technologies are distributed about north of $34^{\circ} \mathrm{N}$ and around 38-24 ka BP. Using an ecological model, we inferred that the extinction rate for these populations on a millennial scale was between $75 \%$ and $100 \%$, and the number of small populations was between 7 and 189. This number of small populations was far less than the local population. We can see from this that although populations from peripheral areas crossed a series of geographical barriers and gradually entered East Asia, their population was too small, and it was difficult for them to sustain the inheritance of their own cultural and technological factors. Furthermore, facing competition and confrontation with different populations, they eventually disappeared
\end{abstract}

Keywords: East Asia, Upper Paleolithic, Geography, Population dispersion, Lithic technology

\section{INTRODUCTION}

East Asia is located on the eastern edge of the Asian continent. It is a geographical area includes China, Mongolia, the Japanese archipelago, and the Korean peninsula. Given the uniqueness of its lithic culture during the Upper Paleolithic, and the evolution and spread of ancient humans in the late Pleistocene, this region has long been an area of interests in paleoanthropology, paleolithic archaeology, geology, and paleoenvironmental science. This vast border region of the Eurasian Continent is connected to Siberia in the north and the Pacific Ocean to the east, and it is bounded by the Himalayas and other mountain ranges in the west and south. During the late Pleistocene, these natural barriers were gradually conquered and crossed by "foreigners" as a result of changes in the environment and population growth among ancient humans. In addition, Levallois and blade techniques, which differed completely from the technology of the local culture, were introduced into the region (Licent, 1925; Boule et al., 1928; Li et al., 2013; Gao et al., 2013a). Thus, the small-flake-tool and pebble-cobble-tool industry traditions of East Asia (Zhang, 1987:1990:1999; Guan et al., 2012) were combined with the external Levallois and blade techniques to form a unique Paleolithic cultural scape in East Asia that differed from North America, Central Asia, West Asia, Europe, and Africa (Gao et al., 2010; Guan et al., 2012).

The Levallois technique was a classic lithic technology in Europe, West Asia, Central Asia, and North Asia (Siberian area) during the Middle Paleolithic that was closely associated with the Neanderthals of that period. In Africa, the published dates of archaeological sites for Levallois-Moustérien type point range from 265-25 ka BP, with most generally centering on 150-40 ka BP (Nicoll, 2009:2010). While the blade technique is considered typically representative of activities by "anatomically modern humans." The earliest evidence in Africa, dating to $500 \mathrm{ka} \mathrm{BP}$, was in the Kathu Pan archaeological site (Wilkins and Chazan, 2012). In Europe, however, it appeared in the final stage of the Middle Paleolithic and had partially evolved from the Levallois technique 
(Bordes, 1968), which then developed further during the Upper Paleolithic. In many cases, Levallois artifacts existed in the initial stage of the Upper Paleolithic, either as traditional forms or as other variants (such as flatfaced cores).

While Levallois and blade techniques were widely distributed in the Eurasian regions, including Europe, West Asia, Central Asia, and North Asia, they only appeared within a limited time and space in the vast geographical area of China. Hence, the question arises: How did these Levallois and blade techniques reach the East Asian region, and what was their impact on the surrounding local technology? It is a fact of human evolution that migrating populations carry their own social productive forces with them and affect the populations around them in varying degrees. Yet, such migrating populations are also influenced by the surrounding productive forces and might even experience the phenomenon of technological substitution. Researchers are still establishing different hypotheses regarding the spread of these social productive forces during the Paleolithic age in East Asia. The present study discusses the possible migration routes of prehistoric humans from the perspectives of geography, paleolithic archaeology, and ecology. Since China and the Mongolian Plateau are the core regions examined here, archaeological materials from the Korean Peninsula and the Japanese archipelago were not included in this study.

\section{GEOGRAPHICAL INTERPRETATION: NATURAL BARRIERS AND CHANNELS}

The mountain ranges surrounding the East Asian regions create many obstructive natural barriers. The Changbai Mountains, Daxing'anling Mountains, Mongolian Plateau, Altai Mountains, Tianshan Mountains, and Tibetan Plateau form natural walls on the northern, western, and southwestern borders, separating the vast East Asian region from North Asia, Central Asia, and South Asia. However, narrow valleys and river systems have existed among the mountains and highlands since the beginning of the early Pleistocene. These intervening valleys and water systems provide sufficient living conditions and resources for biological activities, including those of human beings. Between the Changbai and Daxing'anling Mountains, there are the Songhua, Heilong, and Nen Rivers in the northeast plain. To the south of Lake Baikal, there are the Selenga and Orkhon Rivers in the lowlands. Between the Khangai and Altai Mountains, Zavkhan River, Khovd River, Uvs Lake, and Khar-Us Lake lie in the lowlands. Between the Altai and Tianshan Mountains, there are the Ulungur and Irtys Rivers in the Dzungarian Basin. This area is also very close to the Lake Balkhash water system in Kazakhstan.

If these narrow land strips and river systems are as viewed as arrows, we find that they all point to the regions of Mongolia, Inner Mongolia, Shanxi, Shaanxi, and Ningxia (Figure 1). This area was a hot spot that produced chaotic forms of lithic techniques in the Upper Paleolithic. Combining these geographical features reveals four possible biological migration routes: 1) the lowlands between the Tianshan mountains, which connect the Kazakhstan Highland with many basins in Xinjiang; 2) the Dzungarian Basin, a route with rich river systems and

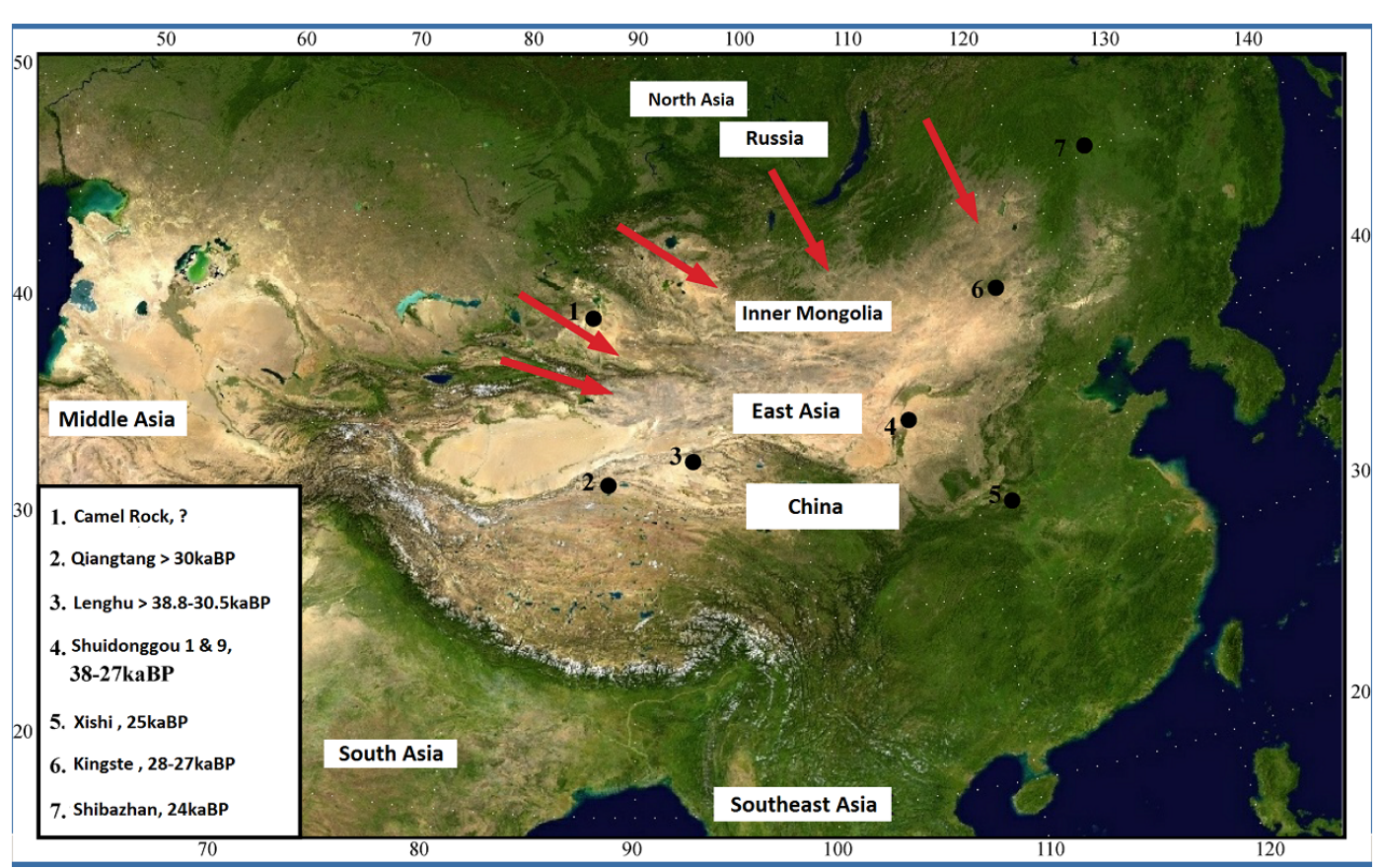

Figure 1. Paleolithic sites with Levallois and blade techniques in China 
oases that connects the Kazakhstan Highland with vast areas of China; 3) the lowlands between the Altai and Khangai mountains, which connect the Siberian plain with the Mongolia Plateau; and 4) the Lake Baikal region, a large plain area with relatively low elevation and several river systems connecting the Siberian plain with the Mongolia plateau.

\section{ARCHAEOLOGICAL INTERPRETATION: ARCHAEOLOGICAL SITES AND LOCALITIES WITH LEVALLOIS AND BLADE TECHNIQUES IN CHINA}

Current evidence suggests that the initial upper Paleolithic culture appeared in the West Asian and Levant regions in 45-40 ka BP; however, the Levallois technique had existed for even longer (Bar-Yosef, 2000; Kuhn et al., 1999). The closer it was to eastern Eurasia, the later these technical factors appeared, showing a trend in which these factors spread west to east (Pei et al., 2012). In the Altai mountain regions of southern Siberia, the earliest archaeological site with Levallois technical features is Kara-Bom, which, dates to 44-42 ka BP (radiocarbon dating) (Vasil'ev et al., 2002). Levallois and blade techniques coexisted around 43-27 ka BP in many areas (Chlachula, 2001; Derevianko, 2010; Kuzmin, 2007; Rybin, 2005; Brantingham et al., 2001b). According to existing data, this technology existed in China after 40 ka BP.

According to published literature, in northern China, coexisting mature Levallois and blade techniques were only found in the primary strata of the Shuidonggou site in Ningxia and Jinsitai site in inner Mongolia (Gao et al., 2013b; Li et al., 2013; Peng et al., 2014; Ningxia Museum et al., 1987; Ningxia Institute of Cultural Relics and Archaeology, 2003). Blade artifacts were found in the strata of archaeological sites in Henan Province and Heilongjiang Province. In Xinjiang Uyghur Autonomous Region, coexisting Levallois-blade artifacts with no archaeological deposits or age indicators were found (Derevianko et al., 2012). On the Tibetan Plateau, a number of archaeological sites with excavated blade artifacts were also found, which had been well radiocarbon dated. The following sections present the details of these sites and localities.

\section{Shuidonggou Site (Localities 1 and 9)}

The Shuidonggou site is located east of Yinchuan, the capital of Ningxia Hui Autonomous Region, in northwest China. Locality 1 (38 $17^{\prime} 55.2$ "N, 106 $30^{\prime} 6$. 7"E) has the longest excavation and research history. This open-air site is famous for its unique lithic composition, which exhibits European Upper Paleolithic features (Boule et al., 1928; Licent and Teilhard de Chardin, 1925; Wang, 1962; Jia et al. 1964), including typical Levallois and blade artifacts (Figure 2a). Researchers generally believe this cultural form arose from movement and exchange among different populations from the east and west of Eurasia during the end of the last glacial period during the Upper Paleolithic (Zhang, 1987). Dating results show that locality 1 was deposited between 38,000 and 29,546 years BP (Table 1) (dating results of $15,000-17,000 \mathrm{BP}$ are considered to have been influenced by late carbon or deposits, thereby seeming younger).

Breuil considered the cultural type that appeared in locality 1 as a transition from the mature Moustérien culture to the initial Aurignacian culture, or a mixture of the two ("En un mot, l'impression schématique qui résulte, pour un typologiste occidental, de l'examen de l'industrie du Choei-tong-keou, c'est qu'elle se présente comme à mi-chemin entre un Moustiérien très évolué et un Aurignacien naissant, ou comme une combinaison entre ces deux elements") (Breuil, 1928). Bordes later re-examined this lithic composition and thought it was a Moustérien Industrial type based on Levallois technology.
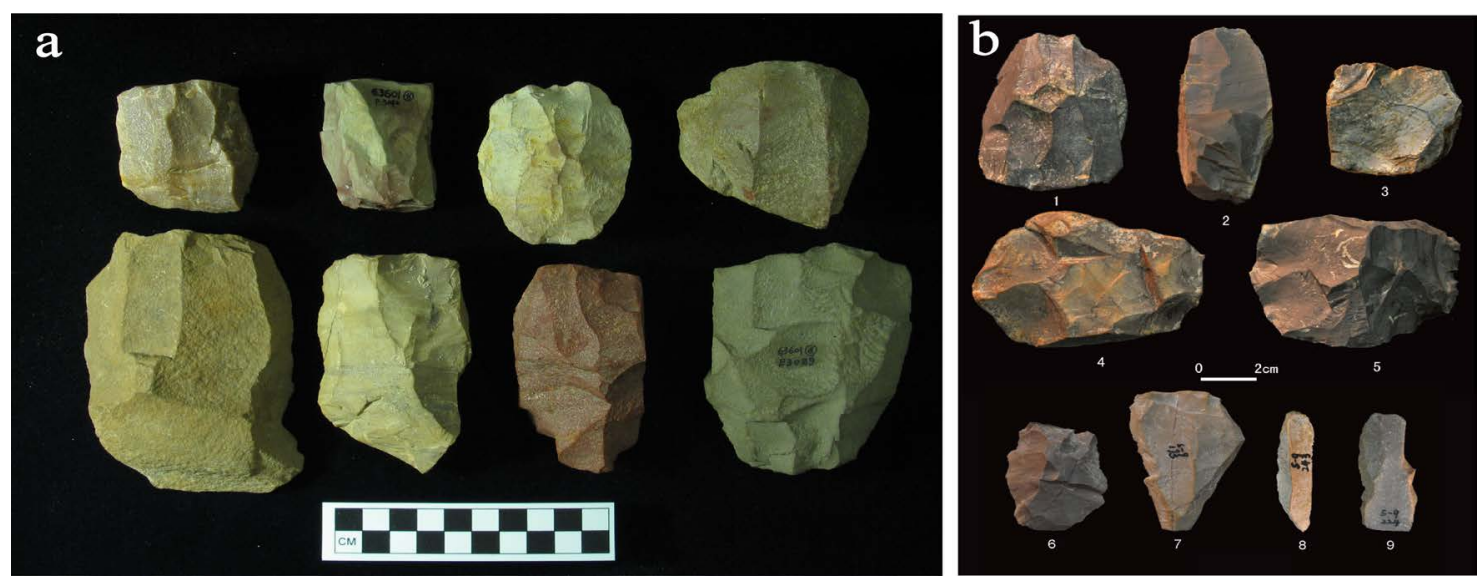

Figure 2. Excavated blade cores in locality 1 of Shuidonggou (a) and lithic artifacts in locality 9 (b) (b1-5: cores; b6-7: Levallois flakes; b8-9: blades) 
Table 1. Dating results of Shuidonggou Locality 1 and 9 (Based on Pei et al., 2012)

\begin{tabular}{|c|c|c|c|c|c|c|}
\hline Location/Stratum & Sample No. & Dating Material & $\begin{array}{c}\text { Dating Results } \\
(\mathrm{aBP})\end{array}$ & Corrected Age & Dating method & Reference \\
\hline SDG1 $3^{\text {rd }}$ Layer & PV-331 & Bone & $16,760 \pm 210$ & $19,919 \pm 257$ & ${ }^{14} \mathrm{C}$ & Li et al. 1987 \\
\hline SDG1 $3^{\text {rd }}$ Layer & IEE1989 & Soil & $28,700 \pm 6,000$ & & $\begin{array}{l}\text { OSL (Optically } \\
\text { Stimulated } \\
\text { Luminescence) }\end{array}$ & Liu et al. 2009 \\
\hline SDG1 $3^{\text {rd }}$ Layer & UGAMS-9682 & Carbon & $36,200 \pm 140$ & $39410 \pm 183$ & $\begin{array}{c}\text { AMS14C } \\
\text { (Accelerator Mass } \\
\text { Spectrometry, C14) }\end{array}$ & Peng et al. 2012 \\
\hline SDG1 $4^{\text {th }}$ Layer & IEE1890 & Soil & $29,300 \pm 4,100$ & & OSL & Liu et al. 2009 \\
\hline SDG1 $4^{\text {th }}$ Layer & IEE1891 & Soil & $32,800 \pm 3000$ & & OSL & Liu et al. 2009 \\
\hline SDG1 $5^{\text {th }}$ Layer & IEE1892 & Fine Sand & $15,800 \pm 1,100$ & & OSL & Liu et al. 2009 \\
\hline SDG1 $6^{\text {th }}$ Layer & 82042 & Equus Teeth & $38,000 \pm 2,000$ & & $\begin{array}{l}\text { U-series (Uranium- } \\
\text { series) }\end{array}$ & Chen et al. 1984 \\
\hline SDG1 $6^{\text {th }}$ Layer & 82043 & Equus Teeth & $34,000 \pm 2000$ & & U-series & Chen et al. 1984 \\
\hline SDG1 $6^{\text {th }}$ Layer & PV-317 & $\begin{array}{l}\text { Calcium } \\
\text { Carbonate } \\
\text { Concretion }\end{array}$ & $25,450 \pm 800$ & $29,546-30,910$ & ${ }^{14} \mathrm{C}$ & Li et al. 1987 \\
\hline SDG1 $6^{\text {th }}$ Layer & IEE1893 & Fine Sand & $17,700 \pm 900$ & & OSL & Liu et al. 2009 \\
\hline SDG1 $6^{\text {th }}$ Layer & IEE1894 & Fine Sand & $34,800 \pm 1,500$ & & OSL & Liu et al. 2009 \\
\hline SDG1 $6^{\text {th }}$ Layer & IEE1895 & Fine Sand & $35,700 \pm 1,600$ & & OSL & Liu et al. 2009 \\
\hline SDG9 $2^{\text {nd }}$ Layer & SDG9-OSL-2 & Fine Sand & $27,400 \pm 3,600$ & & OSL & Unpublished \\
\hline SDG9 $2^{\text {nd }}$ Layer & SDG9-OSL-2 & Fine Sand & $35,900 \pm 6,200$ & & OSL & Unpublished \\
\hline SDG9 $2^{\text {nd }}$ Layer & G07-SDG9-1 & Fine Sand & $29,500 \pm 2,600$ & & OSL & Unpublished \\
\hline SDG9 $2^{\text {nd }}$ Layer & G07-SDG9-2 & Fine Sand & $29,700 \pm 5,300$ & & OSL & Unpublished \\
\hline SDG9 $2^{\text {nd }}$ Layer & G07-SDG9-3 & Fine Sand & $29,400 \pm 6,100$ & & OSL & \\
\hline
\end{tabular}

* Calib Rev 6. 1. 0 (Stuiver and Reimer, 1993) and IntCal09 age calibration database (Reimer et al., 2009) were used for correction

Among them, there were numerous blade artifacts $(31 \%$ were blades or blade cores), $27 \%$ were scrapers, $16.6 \%$ were serrated tools, and $28 \%$ were Upper Paleolithic tool types (Bordes, 1968).

Locality 9 (38 $\left.18^{\prime} 39^{\prime \prime} \mathrm{N}, 106^{\circ} 32^{\prime} 34^{\prime \prime} \mathrm{E}\right)$ is located $7 \mathrm{~km}$ southeast of locality 1 . It was discovered in 2002 and systematically excavated in 2007 . The types of excavated lithic artifacts are very similar to those of locality 1 (Figure $2 \mathrm{~b}$ ) and also show the coexistence of Levallois and blade artifacts. These featured artifacts account for $30.46 \%$ of the total number of excavated specimens (Gao et al., 2013b). The sediment was dated to 35.9-27 ka BP by OSL (Table 1), coinciding highly with locality 1.

\section{Jinsitai Site}

The Jinsitai cave site is located in northeastern Inner Mongolia $\left(45^{\circ} 14^{\prime} 23.4^{\prime \prime} \mathrm{N}, 115^{\circ} 28^{\prime} 32.7^{\prime \prime} \mathrm{E} ; \quad 1401 \mathrm{~m}\right.$ above sea level), about $20 \mathrm{~km}$ south from the ChinaMongolia border. The site was discovered between 2000 and 2001, and the Institute of Vertebrate Palaeontology and Palaeoanthropology of Chinese Academy of Sciences (IVPP, CAS) and the Inner Mongolia Museum reinvestigated the cave in 2012-2013. There are eight layers of sediment in the cave, with the third to eighth layers dating to the Pleistocene. Flakes, gravel, and Levallois artifacts were found in the fifth and sixth layers (Wang et al., 2010; Wang, 2006) with Levallois flakes accounting for $1 \%$ of all flakes. Radiocarbon dating dated the fifth and sixth layers to 28,490-26,989 years BP as shown in Table 2. The site is still being excavated, and it is expected that more detailed stratigraphic and age information will be obtained in the future.

\section{Xishi Site}

The Xishi site is located $20 \mathrm{~km}$ east of Dengfeng City in northern Henan Province (34 ${ }^{\circ} 26^{\prime} 38$. 82" N, $\left.113^{\circ} 13^{\prime} 20.16^{\prime \prime} \mathrm{E}\right)$, about $45 \mathrm{~km}$ south of the Yellow River. This open-air site was discovered in 2010, and many blades, blade cores, and blade tools have been unearthed. At present, the details of the site have not been officially published. The information used in this paper comes from media reports (School of Archaeology and Museology in Peking University and Zhengzhou City Research Institute of Archaeology 2011) and a master's thesis (Gao, 2011). According to the reports, the Xishi site was identified as a lithic workshop. Gao (2011) points out in his thesis that blade artifacts accounted for $4.37 \%$ of the overall composition of lithic artifacts. Human activity was dated to about 25 ka BP through radiocarbon dating. 
Table 2. Radiocarbon dating results of Jinsitai site (Wang et al., 2010)

\begin{tabular}{|c|c|c|c|c|c|}
\hline Lab No. & Samples & Sampling Location & ${ }^{14} \mathrm{C}$ Year (yr BP) & Corrected Age (yr BC)* & Corrected Age (yr BP) \\
\hline BO04478 & Animal bones & 01DAJT4-3B layer & $14,745 \pm 60$ & $16080-15820$ & $18465-17750$ \\
\hline BO04479 & Animal bones & 01DAJT6-5A layer & $23,070 \pm 180$ & & $28490-26989$ \\
\hline BO04480 & Animal bones & 01DAJT3-7C layer & $36,285 \pm 230$ & & $41846-40980$ \\
\hline
\end{tabular}

* Corrected age in original literature (Wang Xiaokun et al., 2010)

** Calib Rev 6.1.0 (Stuiver and Reimer, 1993) and Intcal09 database (Reimeret et al., 2009) were used to correct age

\section{Shibazhan Site}

The Shibazhan site is located $50 \mathrm{~km}$ northeast of Tahe city in Heilongjiang Province (N52 $\left.{ }^{\circ} 2^{\prime} 6^{\prime \prime}, \mathrm{E} 125^{\circ} 24^{\prime} 15^{\prime \prime}\right)$ (Wei and Zhi, 1981; Zhang et al., 2006). This open-air site was discovered in 1975 and systematically excavated in 1975,1976 , and 2005 . Blades play an important role in the overall composition of lithic assemblage and are very similar to those excavated in Shuidonggou. The 2005 research on the excavated materials showed that intact and broken blades accounted for $25.86 \%$ of the total composition (Zhang et al., 2006). OSL dating showed that the site was formed during the Upper Paleolithic, and the age of the blades was $24.7 \pm 1.7 \mathrm{ka}$ BP as shown in Table 3.

\section{Sites and Localities in Xinjiang and the Tibetan Plateau}

Archaeological fieldwork has been conducted in the Xinjiang Uyghur Autonomous Region and the Tibetan Plateau region for many years. In 2004, a Xinjiang Paleolithic survey organized by the Institute of Vertebrate Paleontology and Paleoanthropology, Chinese Academy of Sciences, discovered more than twelve sites in the southern Altai Mountain region. Among the collected artifacts, blades were the main type, which also coexisted with typical Levallois artifacts (Figure 3). This vast area experienced strong natural erosion, and it is difficult to preserve the Pleistocene strata. The lithic artifacts exposed on the surface show severe surface weathering. Therefore, primary strata that could provide significant age indicators were not found in most sites. However, these lithic artifacts show the range of geographical distribution of blade and Levallois techniques in the Altai Mountains, providing valuable evidence of early ancient human migration, dispersion, and interaction.
Many Paleolithic fieldwork surveys have been conducted on the Tibetan Plateau by Chinese and international scholars (Sun et al., 2010; Gao et al., 2008; Yi et al., 2011). Blade cores and other blade artifacts have been found in locality 1 of the Lenghu site $\left(38.85 \mathrm{~N}^{\circ}, 93.41\right.$ $\left.{ }^{\circ} \mathrm{E}\right)$. The upper and lower strata were $30.5 \mathrm{ka} \mathrm{BP}$ and 38.8 ka BP, respectively (Gao et al., 2008; Brantingham et al., 2007). These types of artifacts have also been found in other sites but with no clear age determination, such as the Qiangtang site where artifacts were found with obvious blade and Levallois technical features (Brantingham, 2001a). Brantingham (2007) also described the location of Levallois artifacts in this site, noting that "this site is dated about 30 ka or even earlier" (Brantingham et al., 2007). This vast area needs further Paleolithic fieldwork to establish a more accurate chronological framework and obtain more detailed lithic technology information.

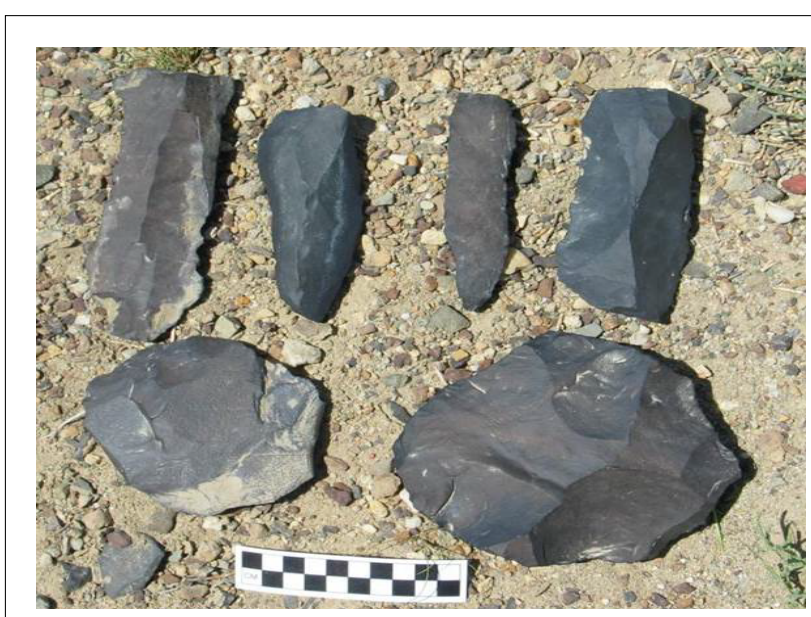

Figure 3: Surface artifacts collected south of the Altai Mountains in Xinjiang

Table 3. OSL dating results of Shibazhan Site (Zhang et al., 2006)

\begin{tabular}{|l|c|c|c|c|c|}
\hline Lab. No. & Sample Field No. & Sample Depth $(\mathrm{m})$ & Measurement rate (Gy/ka) & Equivalent Measurement (Gy) & Age (ka BP) \\
\hline IEE633 & SBZ-01 & 0.1 & $3.99 \pm 0.22$ & $20.05 \pm 0.5$ & $5.0 \pm 0.3$ \\
\hline IEE634 & SBZ-02 & 0.28 & $3.99 \pm 0.22$ & $40.99 \pm 0.9$ & $10.3 \pm 0.6$ \\
\hline IEE635 & SBZ-03 & $0.48^{*}$ & $4.69 \pm 0.25$ & $115.74 \pm 4.6$ & $24.7 \pm 1.7$ \\
\hline IEE636 & SBZ-04 & 0.7 & $5.68 \pm 0.35$ & $294.88 \pm 7.4$ & $51.9 \pm 3.5$ \\
\hline
\end{tabular}

*Stratum containing blade artefacts 


\section{DISCUSSION}

The sites and locations described above are concentrated on $34^{\circ} \mathrm{N}$, and the sites are dated around 38-24 ka BP. In Jilin Province, there are several sites where a certain proportion of excavated long flakes were reported as blades (Chen et al., 2006:2010). These long flakes are very similar to blades in form, but the quantity and technical attributes are very limited. In addition, no corresponding blade cores have been unearthed, and the artifacts account for a very low percentage in the overall composition. Therefore, the nature of these lithic artifacts still needs to be discussed. Thus far, no blade and Levallois artifacts have been reported in the vast areas of southern China, South Asia, and Southeast Asia. Geochronologically, these sites are dated no older than 40 ka BP. The developed river systems in the mountains have provided a wealth of resources for many species, including humans, thus providing a favorable material guarantee for the migration and evolution of these species. Even during the worst of the last glacial period, most species were able to rely on these resources for survival. Under such conditions, during the Upper Paleolithic, some humans living on the periphery moved to East Asia and thus influenced the local population in northern China. In these areas, the external population might have either strongly assimilated the local community or gradually integrated with it. However, due to geographical barriers, environmental changes, and other factors, these populations did not enter the larger areas of eastern or southern China. Rather, they stayed within the previously described geographical range and gradually disappeared around 24 ka BP (Table 4).

Over time, the external populations gradually lost their original cultural elements. This was most likely because they could not continually and steadily inherit specific skills due to their small population size. In addition, once a population declines to a certain level, it can no longer propagate and preserve positive genetic features. Ecologists have proposed two different concepts of extinction namely, local extinction and regional extinction
(Shang, 2010). The former refers to the extinction of a single small population. In the context discussed in this paper, this refers to the extinction of small groups and tribes. The latter refers to the extinction of all small populations within the entire large region. In this paper, it pertains to the extinction of all external populations who moved into the East Asian region. Although human migration and evolution has complexities and special features that are distinct from other species, we can still regard the entire external group who possessed unique lithic technology as a whole "species" and consider the small groups scattered in different geographical ranges as different "small populations" in ecological patches. In the 14 millennia between 38 ka BP and 24 ka BP, the overall "extinction" probability for the external population $(P)$ went from $0 \%$ to $100 \%$ (for human populations, "survival" and "extinction" are relative concepts; in this paper, they refer more to the "survival" and "extinction" of prehistoric technology). In ecology, the formula for calculating the survival probability of a population per unit of time is

$P x=1-(P e)^{x}$ Equation (1)

where $X$ represents the number of small populations in an independent ecological patch, and $P_{\mathrm{e}}$ represents the average extinction probability for each small population. Figure 1 indicates the existence of Levallois and blade techniques in seven major regions in China. If these seven regions are tentatively regarded as seven independent ecological patches and, using one millennium as the time unit, we assume the extinction probability $\left(P_{\mathrm{e}}\right)$ for each small population in each patch on a millennial scale to be a neutral $50 \%$, then the survival probability for the whole population on millennial scale is as follows:

$P_{7}=1-P_{e}^{7}$

This implies that the overall survival probability for the entire population on a millennial scale is $99.22 \%$. The survival probability for the population during the period of $N$ years $\left(P_{n}\right)$ is the product of the probability of nonextinction in consecutive $\mathrm{N}$ years, which is

Table 4. Geographical and chronological ranges of Upper Paleolithic sites with Levallois and blade artifacts

\begin{tabular}{|c|c|c|c|c|c|}
\hline \multirow[b]{2}{*}{ Site and Location } & \multirow[b]{2}{*}{ Latitude \& Longitude } & \multirow[b]{2}{*}{$\begin{array}{l}\text { Strata Age Containing Levallois } \\
\text { and blade artifacts (aBP) }\end{array}$} & \multirow[b]{2}{*}{ Dating Method } & \multicolumn{2}{|c|}{ Artefact Type } \\
\hline & & & & \begin{tabular}{|l|} 
Blade \\
Artifact
\end{tabular} & $\begin{array}{l}\text { Levallois } \\
\text { Artifact }\end{array}$ \\
\hline \multirow[t]{2}{*}{ Shuidonggou 1} & $38^{\circ} 17^{\prime} 55.2^{\prime \prime} \mathrm{N}$ & $38,000 \pm 20,00$ & AMS 14C, U-series, OSL & 0 & 0 \\
\hline & $106^{\circ} 30^{\prime} 6.7^{\prime \prime} \mathrm{E}$ & $25,450 \pm 800$ & AMS 14C, U-series, OSL & 0 & o \\
\hline \multirow[t]{2}{*}{ Shuidonggou 9} & $38^{\circ} 15^{\prime} 39^{\prime \prime} \mathrm{N}$ & $35,900 \pm 6,200$ & OSL & 0 & 0 \\
\hline & $106^{\circ} 32^{\prime} 34^{\prime \prime} \mathrm{E}$ & $27,400 \pm 3,600$ & OSL & 0 & o \\
\hline Xishi & $34^{\circ} 26^{\prime} 38.82^{\prime \prime} \mathrm{N} / 113^{\circ} 13^{\prime} 20.16^{\prime \prime} \mathrm{E}$ & $\sim 25,000$ & $14 \mathrm{C}$ & 0 & $x$ \\
\hline Shibazhan & $52^{\circ} 25^{\prime} 6^{\prime \prime} \mathrm{N} / 125^{\circ} 24^{\prime} 15^{\prime \prime} \mathrm{E}$ & $24,700 \pm 1,700$ & OSL & 0 & $x$ \\
\hline Jinsitai & $45^{\circ} 13^{\prime} \mathrm{N}, 115^{\circ} 22^{\prime} \mathrm{E}$ & $28,490-26,989$ & $14 C$ & 0 & o \\
\hline Lenghu & $38.85 \mathrm{~N}^{\circ}, 93.41^{\circ} \mathrm{E}$ & 38.8-30.5 ka BP & $14 \mathrm{C}$ & 0 & $x$ \\
\hline Qiangtang & & & & 0 & o \\
\hline
\end{tabular}

o-present x-absent 


\section{$P_{n}=(1-P)^{n}$ Equation (2)}

Based on this formula, the survival probability for the overall population over the 14 time units between 38 and $24 \mathrm{ka} \mathrm{BP}$ is

$P_{14}=\left[1-\left(1-P_{7}\right)\right]^{14}$

That is, the overall survival probability is about $89.62 \%$. This result is clearly contrary to reality. Based on our current understanding, survival probability should asymptotically approach $0 \%$ at the end. Therefore, we should evaluate the input parameters. Two parameters were assumed in this calculation: one is the average extinction/survival probability of a single small population, and the other is the number of ecological patches. First, we should evaluate the number of ecological patches assumed based on the discovered archaeological sites; evidently, this number is the most conservative assumption. Each large area should contain several small ecological patches separate from each other. Therefore, in reality, this number should be $\geq 7$, or even much greater. Under this condition, the overall population survival probability on a millennial scale derived above would increase, thereby causing the overall population survival probability in 14 millennia to increase, reaching more than $89.364 \%$. Therefore, the extinction probability $\left(P_{\mathrm{e}}\right)$ for each patch on a millennial scale is necessarily a higher value. By combining equation (1) and equation (2), we obtain the formula for the survival probability for the entire population composed of $X$ small groups during $\mathrm{N}$ years:

\section{$P_{n}=\left[1-(P e)^{x}\right]^{n}$ Equation (3)}

From this, we can derive the following relationships as shown in Table 5 between the extinction probability for a small population per unit time and the survival rate of the entire population:

We can see that among the 7 and 203 ecological patches given, regardless of the number of patches, when the extinction probability for a small population per unit time is below $75 \%$, the overall survival probability is very high. In the case of 7 patches, it reached $13.45 \%$. Therefore,

Table 5. Relationship between the extinction probability of small population per unit time and the survival rate of the entire population.

\begin{tabular}{|c|c|c|c|c|c|c|c|c|c|c|c|c|c|c|c|c|c|c|c|c|c|}
\hline 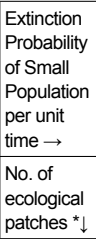 & $5 \%$ & $10 \%$ & $15 \%$ & $20 \%$ & $25 \%$ & $30 \%$ & $35 \%$ & $40 \%$ & $45 \%$ & $50 \%$ & $55 \%$ & $60 \%$ & $65 \%$ & $70 \%$ & $75 \%$ & $80 \%$ & $85 \%$ & $90 \%$ & $95 \%$ & $99 \%$ & $100 \%$ \\
\hline 7 & 1 & 0.9999 & 0.9999 & 0.9998 & 0.9991 & 0.9969 & 0.9910 & 0.9773 & 0.9489 & 0.8960 & 0.8067 & 0.6719 & 0.4947 & 0.3002 & 0.1345 & 0.0370 & 0.0044 & 0.0001 & $\lim _{\rightarrow} 0$ & $\lim _{\rightarrow} \rightarrow 0$ & 0 \\
\hline 21 & 1 & 1 & 1 & 1 & 1 & 1 & 1 & 1 & 0.9999 & 0.9999 & 0.9999 & 0.9996 & 0.9983 & 0.9922 & 0.9672 & 0.8783 & 0.6256 & 0. 1974 & 0.0029 & $\lim \rightarrow 0$ & 0 \\
\hline 28 & 1 & 1 & 1 & 1 & 1 & 1 & 1 & 1 & 1 & 1 & 0.9999 & 0.9999 & 0.9999 & 0.9993 & 0.9955 & 0.9732 & 0.8618 & 0.4711 & 0.0223 & $\lim \rightarrow 0$ & 0 \\
\hline 35 & 1 & 1 & 1 & 1 & 1 & 1 & 1 & 1 & 1 & 1 & 1 & 1 & 0.9999 & 0.9999 & 0.9994 & 0.9943 & 0.9536 & 0.7012 & 0.0786 & $\lim \rightarrow 0$ & 0 \\
\hline 42 & 1 & 1 & 1 & 1 & 1 & 1 & 1 & 1 & 1 & 1 & 1 & 1 & 1 & 0.9999 & 0.9999 & 0.998 & 0.9849 & 0.8448 & 0.1780 & $\lim \rightarrow 0$ & 0 \\
\hline 49 & 1 & 1 & 1 & 1 & 1 & 1 & 1 & 1 & 1 & 1 & 1 & 1 & 1 & 1 & 0.9999 & 0.9997 & 0.9951 & 0.9227 & 0.3065 & $\lim \rightarrow 0$ & 0 \\
\hline 56 & 1 & 1 & 1 & 1 & 1 & 1 & 1 & 1 & 1 & 1 & 1 & 1 & 1 & 1 & 0.9999 & 0.9999 & 0.9984 & 0.9623 & 0.4425 & $\lim _{\rightarrow} 0$ & 0 \\
\hline 63 & 1 & 1 & 1 & 1 & 1 & 1 & 1 & 1 & 1 & 1 & 1 & 1 & 1 & 1 & 1 & 0.9999 & 0.9994 & 0.9818 & 0.5688 & $\lim \rightarrow 0$ & 0 \\
\hline 70 & 1 & 1 & 1 & 1 & 1 & 1 & 1 & 1 & 1 & 1 & 1 & 1 & 1 & 1 & 1 & 0.9999 & 0.9998 & 0.9912 & 0.6759 & $\lim \rightarrow 0$ & 0 \\
\hline 77 & 1 & 1 & 1 & 1 & 1 & 1 & 1 & 1 & 1 & 1 & 1 & 1 & 1 & 1 & 1 & 1 & 0.9999 & 0.9958 & 0.7616 & 0.0001 & 0 \\
\hline 84 & 1 & 1 & 1 & 1 & 1 & 1 & 1 & 1 & 1 & 1 & 1 & 1 & 1 & 1 & 1 & 1 & 0.9999 & 0. 9979 & 0.8272 & 0.0003 & 0 \\
\hline 91 & 1 & 1 & 1 & 1 & 1 & 1 & 1 & 1 & 1 & 1 & 1 & 1 & 1 & 1 & 1 & 1 & 0.9999 & 0.9990 & 0.8762 & 0.0007 & 0 \\
\hline 98 & 1 & 1 & 1 & 1 & 1 & 1 & 1 & 1 & 1 & 1 & 1 & 1 & 1 & 1 & 1 & 1 & 0.9999 & 0.9995 & 0.9119 & 0.0014 & 0 \\
\hline 105 & 1 & 1 & 1 & 1 & 1 & 1 & 1 & 1 & 1 & 1 & 1 & 1 & 1 & 1 & 1 & 1 & 0.9999 & 0.9997 & 0.9377 & 0.0025 & 0 \\
\hline 112 & 1 & 1 & 1 & 1 & 1 & 1 & 1 & 1 & 1 & 1 & 1 & 1 & 1 & 1 & 1 & 1 & 1 & 0.9998 & 0.9561 & 0.0041 & 0 \\
\hline 119 & 1 & 1 & 1 & 1 & 1 & 1 & 1 & 1 & 1 & 1 & 1 & 1 & 1 & 1 & 1 & 1 & 1 & 0.9999 & 0.9691 & 0.0064 & 0 \\
\hline 126 & 1 & 1 & 1 & 1 & 1 & 1 & 1 & 1 & 1 & 1 & 1 & 1 & 1 & 1 & 1 & 1 & 1 & 0.9999 & 0.9783 & 0.0097 & 0 \\
\hline 133 & 1 & 1 & 1 & 1 & 1 & 1 & 1 & 1 & 1 & 1 & 1 & 1 & 1 & 1 & 1 & 1 & 1 & 0.9999 & 0.9848 & 0.0140 & 0 \\
\hline 140 & 1 & 1 & 1 & 1 & 1 & 1 & 1 & 1 & 1 & 1 & 1 & 1 & 1 & 1 & 1 & 1 & 1 & 0.9999 & 0.9894 & 0.0196 & 0 \\
\hline 147 & 1 & 1 & 1 & 1 & 1 & 1 & 1 & 1 & 1 & 1 & 1 & 1 & 1 & 1 & 1 & 1 & 1 & 0.9999 & 0.9925 & 0.0265 & 0 \\
\hline 154 & 1 & 1 & 1 & 1 & 1 & 1 & 1 & 1 & 1 & 1 & 1 & 1 & 1 & 1 & 1 & 1 & 1 & 0.9999 & 0.9948 & 0.0351 & 0 \\
\hline 161 & 1 & 1 & 1 & 1 & 1 & 1 & 1 & 1 & 1 & 1 & 1 & 1 & 1 & 1 & 1 & 1 & 1 & 0.9999 & 0.9963 & 0.0453 & 0 \\
\hline 182 & 1 & 1 & 1 & 1 & 1 & 1 & 1 & 1 & 1 & 1 & 1 & 1 & 1 & 1 & 1 & 1 & 1 & 1 & 0.9987 & 0.0862 & 0 \\
\hline 189 & 1 & 1 & 1 & 1 & 1 & 1 & 1 & 1 & 1 & 1 & 1 & 1 & 1 & 1 & 1 & 1 & 1 & 1 & 0.9991 & 0.1033 & 0 \\
\hline 196 & 1 & 1 & 1 & 1 & 1 & 1 & 1 & 1 & 1 & 1 & 1 & 1 & 1 & 1 & 1 & 1 & 1 & 1 & 0.9993 & 0.1220 & 0 \\
\hline 203 & 1 & 1 & 1 & 1 & 1 & 1 & 1 & 1 & 1 & 1 & 1 & 1 & 1 & 1 & 1 & 1 & 1 & 1 & 0.9995 & 0.1423 & 0 \\
\hline
\end{tabular}

* Since Figure 1 involved 7 major regions, therefore, the number of small ecological patches is assumed to be an integer multiple of 7 . 
Table 6. Relationship between the extinction probability of small populations per unit time and the survival rate of the entire population

\begin{tabular}{|l|l|l|l|l|l|l|l|l|l|l|}
\hline $\begin{array}{l}\text { Extinction probability of } \\
\text { small population per unit } \\
\text { time } \rightarrow\end{array}$ & $75 \%$ & $80 \%$ & $85 \%$ & $90 \%$ & $95 \%$ & $99 \%$ & $99.5 \%$ & $99.6 \%$ & $99.7 \%$ & $99.99 \%$ \\
\hline $\begin{array}{l}\text { No. of ecological patches } \\
\downarrow\end{array}$ & 1 & 1 & 0.9999 & 0.9996 & 0.9202 & 0.0016 & Lim $\rightarrow 0$ & Lim $\rightarrow 0$ & Lim $\rightarrow 0$ & Lim $\rightarrow 0$ \\
\hline 100 & 1 & 1 & 1 & 0.9999 & 0.9936 & 0.0300 & 0.0001 & Lim $\rightarrow 0$ & Lim $\rightarrow 0$ & Lim $\rightarrow 0$ \\
\hline 150 & 1 & 1 & 1 & 1 & 0.9995 & 0.1334 & 0.0016 & 0.0002 & Lim $\rightarrow 0$ & Lim $\rightarrow 0$ \\
\hline 200 & 1 & 1 & 1 & 1 & 0.9999 & 0.3062 & 0.0090 & 0.0016 & 0.0001 & Lim $\rightarrow 0$ \\
\hline 250 & 1 & 1 & 1 & 1 & 0.9999 & 0.4946 & 0.0296 & 0.0067 & 0.0006 & Lim $\rightarrow 0$ \\
\hline 300 & 1 & 1 & 1 & 1 & 1 & 0.6559 & 0.0699 & 0.0192 & 0.0024 & Lim $\rightarrow 0$ \\
\hline 350 & 1 & 1 & 1 & 1 & 1 & 0.7760 & 0.1320 & 0.0430 & 0.0066 & Lim $\rightarrow 0$ \\
\hline 400 & & 1 & & & & & & & \\
\hline
\end{tabular}

the data for $75 \%$ and below can essentially be excluded, and the extreme extinction probability of $100 \%$ can also be excluded. Therefore, only the extinction probabilities for small populations distributed between $75 \%$ and $100 \%$ are worth considering. As discussed above, in reality, the number of small populations carrying Levallois and blade techniques in the seven major regions shown in Figure 1 could reach dozens or even more. Thus, the data for small populations fewer than 7 can be excluded. If the number of small populations is $<7$, then the extinction rate for small populations per unit time of less than or equal to $75 \%$ would imply a $13.45 \%$ overall survival rate. We can therefore exclude the extinction rates for small populations per unit time of less than $75 \%$. In the situation where the number of small populations is $\geq 189$, if the extinction rate for small populations per unit time is $<99 \%$, then the overall survival rate will be greater than $10.34 \%$ (Table 5).

Thus, the extinction rate for a small population on a millennial scale can be set between $75 \%$ and $100 \%$, and the number of small populations can be set between 7 and 189.

We will now again observe the local population that used the traditional small-flake-tool industry as the mainstream. According to Xu Xin's (2012) statistics, within the geographical range discussed in this paper, the number of Upper Paleolithic sites officially recorded in the literature is about 400. Other archaeological sites and localities found in various types of fieldwork surveys but not officially published number more than one hundred. Among these hundreds of archaeological sites and localities, about half are dated between 38 and 14 ka BP. Based on this information, we can input these data into equation (3) and obtain another set of data as shown in Table 6 . When the number of ecological patches reaches 200 , the overall survival rate in the extreme cases $(0.16 \%$ when the extinction probability for a small population per unit time is $99.5 \%$; $13.34 \%$ when the extinction probability for a small population per unit time is 99\%) still has sufficient tolerance. When the number of ecological patches exceeds 200, the survival probability for the whole population results in geometric growth. We can see from this that although populations from peripheral areas crossed a series of geographical barriers and gradually entered East Asia, their population was too small, and it was difficult for them to sustain the inheritance of their own cultural and technological factors. Furthermore, facing competition and confrontation with different populations, they eventually disappeared.

\section{CONCLUSION}

Regarding the western region of the Eurasian continent, there is broad consensus among researchers on the technical definition of "Initial Upper Paleolithic." This includes: 1) the production of blades, with blade cores possessing both Middle and Upper Paleolithic technical features; 2) a high percentage of blades used for making tools; 3) blades and blade cores with repair platforms; and 4) long Levallois point (Kuhn, 1999). Brantingham also discussed the regional differences in lithic assemblage artifacts and performed a comparative study of the assemblages of the Middle and Upper Paleolithic in North Asia and those with blade factors in the Mongolian Plateau and Northeast China (Brantingham et al., 2001b). The types, production methods, and raw-material utilization of Levallois and blade artifacts in East Asia had various differences with other regions. Such differences have not been adequately studied due to limited and inaccurate information on archaeological sites. At present, however, all the descriptive literature adequately identifies the geographical and age ranges of these different technology types.

From another perspective, Paleolithic archaeological exploration has been conducted for almost a century in East Asia. However, the archaeological sites found with Levallois and blade techniques are very limited. This highlights the scarcity of such cultural factors in this region; it was only around 40 ka BP that it was gradually infiltrated by "foreigners" from the west and north. In crossing the geographic barriers, these ancient populations (both anatomically modern humans and archaic Homo sapiens) traveled over land and water, migrating over long distances. During the journeys, they gradually lost their own lithic technology because of their limited population 
size. This could characterize the landscape of human migration during the Upper Paleolithic in East Asia.

Extensive morphological comparisons of Levallois and blade techniques still need to be performed to more accurately assess the evolutionary patterns of lithic technology both east and west of Eurasia and to explore the reasons for technological revolution. In this way, we can eventually recover the progression of outsiders from their entrance into East Asia to their final disappearance.

\section{ACKNOWLEDGMENT}

This project was supported by the National Natural Science Foundation of China (No. 41772024), and National Basic Research Program of China (No: 2015CB953803).

\section{REFERENCES}

Bar-Yosef O and Pilbeam DR (2000). The geography of Neanderthals and modern humans in Europe and the Greater Mediterranean, Peabody Museum of Archaeology and Ethnology. Cambridge.107-165.

School of Archaeology and Museology, Institute of Cultural relics and archaeology of Zhengzhou, (2011) First time blade unearthed from hinterland of Central China: the breakthrough of Xishi site in the city of Dengfeng, Henan Province (in Chinese), China, Beijing.

Bordes F (1968). The old stone age, McGraw-Hill, New York, 30.

Boule M, Breuil H, Licent E and Teilhard P (1928). Pateolithique de la Chine, Institute of Human Palaeontology, Paris.

Brantingham PJ, Krivoshapkin A, Li J and Tserendagva Y (2001). The initial Upper Paleolithic in northeast Asia. Curr. Anthropol. 42: 735-746.

Brantingham PJ, Olsen JW and Schaller GB (2001). Lithic Assemblages from the Chang Tang Region, Northern Tibet. Antiquity. 75: 319-327.

Brantingham PJ, Gao X, Olsen JW, Ma H, Rhode D, Zhang $\mathrm{H}$ and Madsen DB (2007). A short chronology for the peopling of the Tibetan Plateau. Elsevier. United State. 9: 129-150.

Boule M, Breuil H, Licent E, Teilhard P, eds. Le Paléolithique de la Chine (1928). Archives de l'institut de Paléontologie Humaine. Memorie 4. Paris. 29: 392-395.

Chen TM, Yuan SX and Gao SJ (1984). The study on uranium-series dating of fossil bones and an absolute age sequence for the main Paleolithic sites of North China, Acta. Anthropologica. Sinica. 3: 259-269.

Chen Q, Wang C, Fang Q and Zhao H (2006). Paleolithic artifacts from Shirengou Site, Helong country, Yanbian city. Acta. Anthropologica. Sinica. 25: 106-114.

Chen Q, Zhao H, Fang Q and Wang C (2010). A
Preliminary Excavation of the Shirengou Paleolithic Site, Helong County, Yanbian City in 2005. Acta. Anthropologica. Sinica. 29: 105-114.

Chlachula J (2001). Pleistocene climate change, natural environments and palaeolithic occupation of the Altai area, west-central Siberia. Quatern. Int. 80-81: 131-167.

Derevianko AP (2010). There scenarios of the Middle to Upper Paleolithic transition: scenario 1: the Middle to Upper Paleolithic Transition in Northern Asia. Archaeo, Ethnol and Anthropol of Eurasia 38: 2-32.

Gao X, Wang H and Guan Y (2013). Research at Shuidonggou: New Advance and New Perceptions. Acta. Anthropologica. Sinica. 32: 121-132.

Gao X, Wang H, Pei S and Chen F (2013). Shuidonggou: Excavation and Research (2003-2007) Report (in Chinese). Science Press. Beijing.

Gao X, Zhang X, Yang D, Shen C and Wu X (2010). Revisiting the origin of modern humans in China and its implications for global human evolution, Science China Earth Sciences. 53: 1927-1940.

Xing G, Zhou Z and Ying G (2008). Human cultural remains and adaptation strategies in the Tibetan Plateau margin region in the late Pleistocene. Quat. Sci. 28: 969977.

Guan Y, Gao X, Li F, Pei S, Chen F and Zhou Z (2012). Modern human behaviors during the late stage of the MIS3 and the broad spectrum revolution: Evidence from a Shuidonggou Late Paleolithic site. Chinese. Science. Bulletin. 57: 379-386.

Jia L, Gai P and Li Y (1964). New materials from Shuidonggou Paleolithic site (in Chinese), Vertebrata PalAsiatica. 8: 75-86.

Kuhn SL, Stiner MC and Gulec E (1999). Initial Upper Paleolithic in south-central Turkey and its regional context: a preliminary report. Antiquity. 73: 505-517.

Kuzmin Y V (2007). Chronological framework of the Siberian Paleolithic: recent achievements and future directions. Radiocarbon. 49: 757-766

Li XG, Liu GL, Liu GY (1987). 14C dating report (PV) I (in Chinese). In: The proceeding of Pleistocene glacial and geology (IV)(in Chinese). Geology Press. Beijing. 16-38.

Li F, Gao X, Chen F, Pei S, Zhang Y, Zhang X, Liu D, Zhang S, Guan Y, Wang H and Kuhn SL (2013). The development of Upper Palaeolithic China: new results from the Shuidonggou site. Antiquity. 87: 368-383.

Licent E and Chardin PT (1925). Le Paleolithique, de la Chine. L'Anthropol, 25: 201-234.

Liu DC, Wang XL, Gao X, Xia ZK, Pei SW, Chen FY, Wang HM (2009). Progress in the stratigraphy and 
geochronology of the Shuidonggou site, Ningxia, North China. Chinese Science Bulltin. 54: 3880-3886.

Nicoll K (2009). Evidence of Lewallois technology at a Middle Stone Age open air site along the AngolaNamibia border. Antiquity. 83.

Nicoll K (2010). Geomorphic development and Middle Stone Age archaeology of the Lower Cunene River, NamibiaAngola Border. Quaternary. Sci. Rev. 29: 1419-1431.

Ningxia Archaeological Institute (2003). Shuidonggou: Report of the Excavation of 1980 (in Chinese), Science Press, Beijing.

Ningxia Museum, Ningxia Geological Survey (1987). Excavation of the Shuidonggou site in 1980 (in Chiese), Acta Archaeolica Sinica 6: 439-448.

Pei S, Gao X, Wang H, Kuman K, Bae CJ, Chen F, Guan Y, Zhang Y, Zhang X, Peng F, Li X (2012). The Shuidonggou site complex: new excavations and implications for the earliest Late Paleolithic in North China. J. Archaeol. Sci. 39: 3610-3626.

Peng F, Wang HM and Gao X (2014). Blade production of Shuidonggou Locality 1 (Northwest China): A technological perspective. Quatern. Int. 347: 12-20.

Peng F, Gao X, Wang HM, Chen FY, Liu DC and Pei SW (2012). An engraved artifact from Shuidonggou, an Early Late Paleolithic Site in Northwest China. Chin. Sci. Bull. 57: 4594-4599.

Reimer PJ, Baillie MGL, Bard E, Bayliss A, Beck JW, Blackwell PG, Bronk RC, Buck CE, Burr G S, Edwards RL, Friedrich M, Grootes PM, Guilderson TP, Hajdas I, Heaton TJ, Hogg AG, Hughen K A, Kaiser KF, Kromer B, McCormac FG, Manning SW, Reimer RW, Richards DA, Southon JR, TalamoS, Turney CSM, van der PJ and Weyhenmeyer CE (2009). IntCal09 and Marine09 radiocarbon age calibration curves. Radiocarbon. 51: 1111-1150.

Rybin EP (2005). Land use and settlement patterns in the mountain belt of south Siberia: mobility strategies and the emergence of 'cultural geography' during the middleto-upper Palaeolithic transition. Bull Indo Pac Prehist. Associat. 25: 79-87.

Shang YC (2010). General ecology (third edition). Peking University Press. Beijing

Stuiver M, Reimer PJ (1993). Extended 14C database and revised CALIB radiocarbon calibration program. Radiocarbon. 35: 215-230.
Sun Y, Lai Z, Long H, Liu X and Fan Q (2010). Quartz OSL dating of archaeological sites in Xiao Qaidam Lake of the NE Qinghai-Tibetan Plateau and its implications for palaeoenvironmental changes. Quat. Geochronol. 5: 360-364.

Vasil'ev SA, Kuzmin Y, Orlova L and Dementiev V (2002). Radiocarbon-based chronology of the Paleolithic of Siberia and its relevance to the peopling of the New World. Radiocarbon. 44: 503-530.

Wang C (2006). A study of the stone artifacts from the Paleolithic Jinsitai Cave sie (In Chinese), Archaeology Department, Jinlin University, Changchun.

Wang X, Wei J, Chen Q, Tang Z and Wang C (2010). A preliminary study on the excavation of the Jinsitai Cave site. Acta. Anthropologica. Sinica. 29: 15-32.

Wang Y (1962). The Shuidonggou Paleolithic site. Archaeology. 11: 588-589.

Wei Z and Gan Z (1981). The new dicovered Paleolithic remains in Shibazhan site in Huma County. Seeking Truth. 118-121.

Wilkins J and Chazan M (2012). Blade production $\sim 500$ thousand years ago at Kathu Pan 1, South Africa: support for a multiple origins hypothesis for early Middle Pleistocene blade technologies. J. Archaeol. Sci. 39: 1883-1900.

Xu X (2012). The data analysis of Paleolithic sites in China. Master thesis. Institute of Vertebrate Paleontology and Paleoanthropology. Beijing.

Yi M, Gao X, Zhang X and Sun Y (2011). A preliminary report on investigations in 2009 of some prehistoric sites in the Tibetan Plateau marginal region. Acta. Anthropologica. Sinica. 30: 124-136.

Zhang S (1987). The paleolithic culture in China. Tianjin Science and Technique Press, Tianjin.

Zhang S (1990). Reginal industrial gradual advance and cultural exchange of Paleolithic in North China. Acta. Anthropologica. Sinica. 9: 322-333.

Zhang S (1999). On the important advancements of the Paleolithic archaeology in China since 1949. Acta. Anthropologica. Sinica. 18: 193-214.

Zhang X, Yu H and Gao X (2006). New findings and dates of the Shibazhan Paleolithic Site, Heilongjian Province. Acta. Anthropologica. Sinica. 25: 115-128. 